\title{
The case for autoimmune neurology
}

Josep Dalmau, MD, PhD

Correspondence to

Dr. Dalmau:

jdalmau@clinic.ub.es

Neurol Neuroimmunol Neuroinflamm

2017;4:e373; doi: 10.1212/ NXI.0000000000000373
This year, at the Annual Meeting of the American Academy of Neurology, the inaugural session of the "Autoimmune Neurology" section was held. Attendance and enthusiasm were high. The term "Autoimmune Neurology" is currently used to describe the emerging field that encompasses "immune-inflammatory" diseases of the nervous system other than MS. Autoimmune Neurology has emerged over the past 15 years with an expanding list of disorders and has attracted the attention of colleagues from other specialties. The identification of these diseases has facilitated the diagnosis and often successful treatment for patients who previously were considered to have idiopathic or poorly defined diseases. In addition, studies of the underlying pathogenic mechanisms have improved our understanding on how autoantibodies directly alter the function of neurons, astrocytes, and synaptic networks, resulting in an extraordinary variety of neuropsychiatric symptoms. All AAN members interested in participating and receiving news about the Autoimmune Neurology section should consider joining "Synapse" (Synapse AAN Online Communities), the official communication platform of the AAN Sections.

A remarkable parallelism can be established between the growing interest in Autoimmune Neurology and this journal, Neurology ${ }^{\circledR}$ Neuroimmunology \& Neuroinflammation, which was inaugurated in 2014 partly in response to the increasing number of excellent manuscripts focused on these fascinating disorders. This July issue of Neurology: Neuroimmunology \& Neuroinflammation reflects the forward momentum of the field, with an abundance of interesting articles that make it difficult to choose which to highlight in this Editors Corner.

Among the articles is a study by Rothhammer et al., ${ }^{1}$ which reports that agonists of aryl hydrocarbon receptor (AHR) in serum are dynamically modulated during the course of MS. The AHR is a ligandactivated transcription factor that has critical regulatory functions of the innate and adaptive immune responses relevant to the pathogenesis of autoimmune diseases such as irritable bowel disease and MS. Agonists of AHR come from a variety of sources and can be endogenous metabolic products (e.g., L-Kynurenine), synthetic (e.g., laquinimod) or derive from the diet, environmental pollutants, or commensal bacteria. In several disease models, activation of AHR by a variety of agonists produces nuclear translocation and control of specific transcriptional programs and has been demonstrated to result in anti-inflammatory and neuroprotective effects. These authors have previously shown that AHR agonists generated by the gut microbiome can be detected in the CNS where they dampen CNS inflammation by activating AHR in resident cells. ${ }^{2}$ In the current study, the authors detected a global decrease of circulating AHR agonists in patients with relapsing-remitting MS compared with healthy controls. By contrast, during acute stages of CNS inflammation in active MS or clinically isolated syndrome (CIS), the authors found that AHR agonist activity was increased. Moreover, AHR ligand levels in patients with benign MS or mild clinical impairment were unchanged compared with healthy controls. These data demonstrate that the serum AHR agonists are dynamically modulated during the course of MS and could lead to the development of biomarkers to monitor disease activity as discussed in an Editorial Comment by Sabatino and Zamvil. ${ }^{3}$

The study by Moser et al. ${ }^{4}$ in this issue also implicates dysregulation of the gut microbiome in autoimmunity. In their proof-of-concept study, the authors examined mucosal specimens obtained during ileocolonoscopy from 15 treatment-naive patients with CIS or early relapsing MS. They also evaluated fecal samples from the patients for short-chain fatty acids (SCFAs), which have been implicated in mediating regulatory intestinal immune responses, including Treg homeostasis. The results demonstrated that compared with healthy controls, patients with CIS or MS had significantly fewer dendritic cells (DCs), CD103+ tolerogenic DCs, and Tregs in their distal colon as well as significantly lower total fecal content of SCFAs and, in particular, of butyrate and acetate.

From the ICREA-IDIBAPS, Hospital Clínic, University of Barcelona, Spain; and Department of Neurology, University of Pennsylvania. Funding information and disclosures are provided at the end of the editorial. Go to Neurology.org/nn for full disclosure forms.

This is an open access article distributed under the terms of the Creative Commons Attribution-NonCommercial-NoDerivatives License 4.0 (CC BY-NC-ND), which permits downloading and sharing the work provided it is properly cited. The work cannot be changed in any way or used commercially without permission from the journal. 
These results indicate that homeostasis of colon DCs and Tregs is disturbed in patients with CIS and MS and may be associated with the SCFA depletion. Although the authors state that these results cannot serve to establish a causal relationship with the demyelinating disease, they provide a very nice discussion of how these changes in the immune constitution of the gut could be clinically relevant.

Joubert et al..$^{5}$ report a novel clinical manifestation of Caspr2 antibody-associated encephalitis consisting of paroxysmal or episodic ataxia. Their article describes a 61-year-old patient with limbic encephalitis who developed short-lasting (less than 1 minute) episodes of slurred speech, gait ataxia, and limb dysmetria. These episodes repeated 3-4 times every day and showed a rapid response to immunotherapy. Based on this observation, the authors retrospectively identified episodic ataxia in 5 of 37 patients with Caspr2 antibody-associated encephalitis, all with limbic involvement (and none with neuromyotonia or Morvan syndrome). In these additional cases, the acute symptoms of cerebellar dysfunction lasted between a few minutes and 2 hours and were often triggered by orthostatism. In one of the patients, the episodes preceded by 7 months the development of full-blown autoimmune encephalitis (AE). In 4 of 5 cases, the ataxic episodes responded to immunotherapy and in 1 improved spontaneously. The underlying mechanism is unknown, but the authors emphasize the remarkable similarity between these episodes and those of episodic ataxias related to hereditary channelopathies involving KCNA1 (a gene coding for the voltagegated potassium channel $\mathrm{Kv1.1}$ ) and $C A C N A 1 A$ (Cav2.1 subunit of the $\mathrm{P} / \mathrm{Q}$ type voltage-gated calcium channel).

Probasco et al. $^{6}$ report the fludeoxyglucose (FDG)PET/CT findings in 61 patients with AE, 32 of them seropositive for antibodies. Fifty-two (85\%) had abnormal FDG-PET/CT, showing isolated hypometabolism in 42 (68\%), isolated hypermetabolism in 2 (3\%), and mixed areas of hypermetabolism and hypometabolism in 8 (13\%). Overall, abnormal metabolic findings occurred more frequently than CSF inflammation (62\%), abnormal MRI (40\%), and abnormal initial EEG (30\%). The authors did not find differences across age groups, antibody status, antibody class, or type of AE. This article has several limitations discussed by the authors, related to the small number of patients with some subtypes of AE; for example, the subsets of patients with anti-NMDAR or anti-VGKC complex encephalitis more often had hypermetabolism than those with other types of AE. Longitudinal studies on the pattern of the FDG-PET/CT abnormalities along the course of the disease were not obtained; this has been suggested to be important in patients with anti-NMDAR encephalitis and might as well be important in other AE. Nevertheless, the sensitivity of FDG-PET/CT in AE was higher than any of the other paraclinical tests and seemed to be unaltered by corticosteroids and sedatives, suggesting a potential, yet undefined, role of FDG-PET/CT in the diagnosis, follow-up, or prognosis of $\mathrm{AE}$.

In addition to these studies, this July issue of Neurology: Neuroimmunology \& Neuroinflammation contains 21 articles and an Editorial Comment on AHR as a potential surrogate marker of MS disease activity, which I hope will catch your interest.

\section{STUDY FUNDING}

No targeted funding reported.

\section{DISCLOSURE}

J. Dalmau is the editor of Neurology: Neuroimmunology \& Neuroinflammation; is on the editorial board for Neurology ${ }^{\circledR}$, UpToDate; holds patents for and receives royalties from Ma2 autoantibody test, NMDA receptor autoantibody test, GABA(B) receptor autoantibody test, GABA(A) receptor autoantibody test, DPPX autoantibody test, and IgLON5 autoantibody test; and receives research support from Euroimmun, NIH, Fundació CELLEX, and Instituto Carlos III (Fondo de Investigaciones Sanitarias). Go to Neurology.org/nn for full disclosure forms.

\section{REFERENCES}

1. Rothhammer V, Borucki DM, Garcia Sanchez MI, et al. Dynamic regulation of serum aryl hydrocarbon receptor agonists in MS. Neurol Neuroimmunol Neuroinflamm 2017;4:e359. doi: 10.1212/NXI.0000000000000359.

2. Rothhammer V, Mascanfroni ID, Bunse L, et al. Type I interferons and microbial metabolites of tryptophan modulate astrocyte activity and central nervous system inflammation via aryl hydrocarbon receptor. Nat Med 2016;22:586-597.

3. Sabatino JJ, Zamvil SS. Aryl hydrocarbon receptor activity may serve as a surrogate marker for MS disease activity. Neurol Neuroimmunol Neuroinflamm 2017;4:e366. doi: 10.1212/NXI.0000000000000366.

4. Moser AM, Spindelboeck W, Strohmaier H, et al. Mucosal biopsy reveals immunologic changes of the colon in patients with early MS. Neurol Neuroimmunol Neuroinflamm 2017;4:e362. doi: 10.1212/NXI.0000000000000362.

5. Joubert B, Gobert F, Thomas L, et al. Autoimmune episodic ataxia in patients with anti-CASPR2 antibody-associated encephalitis. Neurol Neuroimmunol Neuroinflamm 2017;4:e371. doi: 10.1212/NXI.0000000000000371.

6. Probasco JC, Solnes L, Nalluri A, et al. Abnormal brain metabolism on FDG-PET/CT is a common early finding in autoimmune encephalitis. Neurol Neuroimmunol Neuroinflamm 2017;4:e352. doi: 10.1212/NXI.0000000000000352. 


\section{Neurology \\ Neuroimmunology \& Neuroinflammation}

The case for autoimmune neurology

Josep Dalmau

Neurol Neuroimmunol Neuroinflamm 2017;4;

DOI 10.1212/NXI.0000000000000373

This information is current as of July 6, 2017

\section{Updated Information \& Services}

References

Permissions \& Licensing

\section{Reprints}

including high resolution figures, can be found at:

http://nn.neurology.org/content/4/4/e373.full.html

This article cites 6 articles, 0 of which you can access for free at: http://nn.neurology.org/content/4/4/e373.full.html\#\#ref-list-1

Information about reproducing this article in parts (figures,tables) or in its entirety can be found online at:

http://nn.neurology.org/misc/about.xhtml\#permissions

Information about ordering reprints can be found online: http://nn.neurology.org/misc/addir.xhtml\#reprintsus

Neurol Neuroimmunol Neuroinflamm is an official journal of the American Academy of Neurology.

Published since April 2014, it is an open-access, online-only, continuous publication journal. Copyright

Copyright (C) 2017 The Author(s). Published by Wolters Kluwer Health, Inc. on behalf of the American Academy of Neurology.. All rights reserved. Online ISSN: 2332-7812.

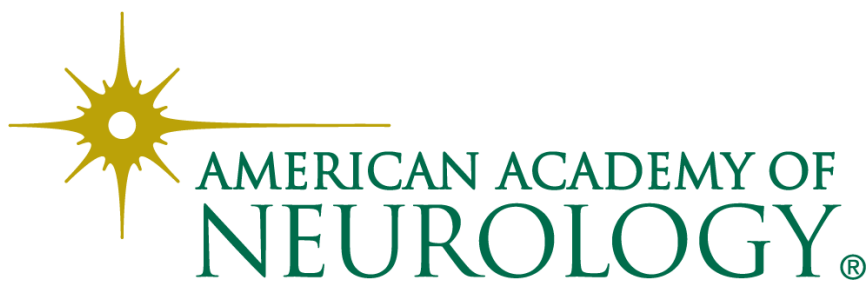

